\title{
PENGARUH KOMPENSASI DAN KOMPETENSI TERHADAP KINERJA PENGAWAS SEKOLAH
}

\author{
Domingos Belo Soares \\ Gede Riana \\ ${ }^{1}$ Fakultas Ekonomi dan Bisnis Universitas Udayana, Bali, Indonesia 2015 \\ e-mail :dbelosoares@yahoo.com
}

\begin{abstract}
Effects of Compensation and Competence on School Supervisors' Performance. Various forms of effort that can be done for the development of human resources, is how to improve the well-being and ability of employees with compensation and competency to improve employee performance. The purpose of this study was to determine whether there is a relation between compensation and competency together affected the school superintendent performance in the Director General Inspection of the ministry of education in East Timor. The approach is to use data from a questionnaire survey trafficking in Director General Inspection of the ministry of education in East Timor. The population for this study is the schools superintendent of totaling 65 persons, while the analysis used by using multiple linear regression analysis to see the effect between the dependent variable and independent variable data is processed with SPSS 17.0 (Statistical Package for Social Science). Results of Simultaneously analysis, variable compensation and competence have an influence on the performance of the school superintendent, the partial analysis compensation have an influence on the performance of the school superintendent, while competence has no effect on the performance of the school superintendent. These results are not consistent with the hypothesis and previous studies, that's compensation and competency variable together a significant effect on performance. For that further studies need to add another variable into the independent variables.
\end{abstract}

Keywords: Compensastion, Competency, School Superintendent Performance

\begin{abstract}
Abstrak: Pengaruh Kompensasi Dan Kompetensi Terhadap Kinerja Pengawas Sekolah. Berbagai bentuk usaha yang dapat dilakukan untuk pengembangan sumber daya manusia adalah bagaimana memperbaiki kesejahteraan dan kemampuan karyawan dengan kompensasi dan kompetensi untuk meningkatkan kinerja karyawan. Tujuan penelitian ini adalah untuk mengetahui ada tidaknya hubungan antara kompensasi, dan kompetensi secara bersama-sama berpengaruh terhadap kinerja pengawas sekolah pada Direção Inspeção Geral di Kementrian Pendidikan Timor Leste. Pendekatan adalah menggunakan data dari pengedaran survey kuesioner di Direção Inspeção Geral di Kementrian Pendidikan Timor Leste. Populasi dalam penelitian ini adalah seluruh pengawas sekolah berjumlah 65 orang, sedangkan analisis yang digunakan dengan menggunkan analisis regresi linier berganda untuk melihat pengaruh antar varibel dependen dan varibel independen data diolah dengan bantuan perangkat lunak SPSS 17.0 (Statistical Package for Social Science). Hasil analisis secara simultan variabel kompensasi, dan kompetensi mempunyai pengaruh terhadap kinerja pengawas sekolah, secara parsial kompensasi mempunyai pengarui terhadap kinerja pengawas sekolah, sedangkan kompetensi tidak berpengaruh terhadap kinerja pengawas sekolah. Hasil tersebut tidak sesuai dengan hipotesis dan penelitian terdahulu bahwa variable kompensasi dan kompetensi secara bersama-sama berpengaruh signifikan terhadap kinerja. Untuk itu penelitian selanjutnya perlu menanbah variable lain dalam variable independent.
\end{abstract}

Kata kunci : Kompensasi, Kompetensi, Kinerja Pengawas. 


\section{PENDAHULUAN}

Organisasi merupakan perkumpulan antara dua orang atau lebih yang bekerja sama dan mempunyai ikatan untuk mencapai suatu tujuan bersama (Gaol, 2014). Keberhasilan organisasi dalam menjalankan misinya dapat diukur dengan kinerja organisasi, kinerja organisasi dapat diukur dengan kinerja masingmasing individu yang berperang didalamnya. Kinerja suatu organisasi akan lebih baik bila setiap individu yang bekerja didalamnya dapat menjalankan peranannya dengan baik dalam menjalankan strategi organisasi (Wibowo, 2010).

Kinerjamerupakangambaranmengenai tingkat pencapaian pelaksanaan program kegiatan atau kebijakan dalam mewujudkan sasaran, tujuan, visi, misi dan organisasi yang dituangkan melalui perencanaan estrategis suatu organisasi. Kinerja dapat diketahui dan diukur jika individu atau sekelompok yang telah mempunyai kriteria atau standar keberhasilan tolok ukur yang ditetapkan oleh organisasi (Moeheriono, 2009).

Undang-Undang Dasar Pendidikan tersedia dalam Pasal 42 istilah umum dan relevansi dengan inspektorat pendidikan, untuk memajukan dan menjamin efisiensi, efektivitas dan kualitas sistem pendidikan. Ketentuan Pasal 44 Keputusan-UndangUndang Nomor 22/2010, tanggal 9 Desember. Undang-undang ini menetapkan pentingnya strategis departemen Kementerian Pendidikan, pemantauan, pengawasan dan pemeriksaan, pelaksanaan kebijakan pendidikan yang berhubungan dengan sekolah dan mutu pendidikan.

Keberhasilan program inspeksi pengajaran pendidikan tentu dipengaruhi oleh banyak faktor yang berada di sekitarnya yang membutuhkan kompetensi aparatur pengelola yang berkualitas, dan juga tingkat partisipasi seluruh elemen yang terlibat di dalamnya. Berdasarkan hasil pengukuran kinerja Inspeção Geral do Ministerio da Educação de Timor Leste dalam lima tahun terakhir melalui pengukuran pencapaian sasaran kegiatan inspeksi dapat dilihat pada Gambar 1.1.

Pada Gambar 1.1 ditunjukkan grafik

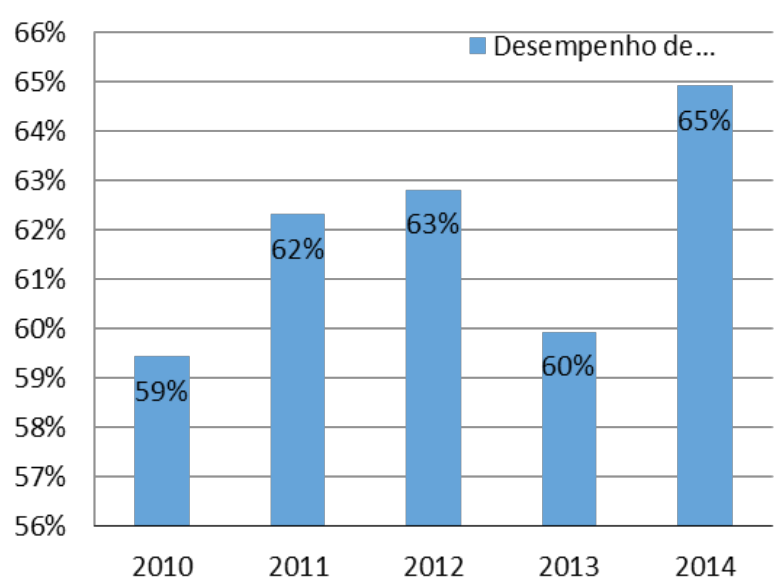

Gambar 1.1 Grafik Kinerja Inspeksi Kementerian Pendidikan Timor Leste

Sumber: Resultado Avaliação do Servisços Inspeção Geral do ME - RDTL, 2014

hasil pencapai kerja (kinerja) kementerian pendidikan melalui program inspeksi dalam lima tahun terakhir belum mencapai target yang diharapkan. Kinerja Inspeção Geral do Ministerio da Educação de Timor Leste dalam lima tahun terakhir dipengaharui oleh kinerja para pengawas sekolah yang belum maksimal. Kinerja pengawas sekolah diukur dengan hasil evaluasi dari tiga program yang dijalakan dalam melakukan program inspeksi. Ketiga program inspeksi yaitu inspeksi rutin (inspeção rutina), inspeksi pencegahan (inspeção preventiva), dan inspeksi investigasi (inspeção insvestigativa). Hasil evaluasi ketiga program inspeksi dalam lima tahun terakhir dapat dilihat pada Gambar 1.2 dibawah ini.

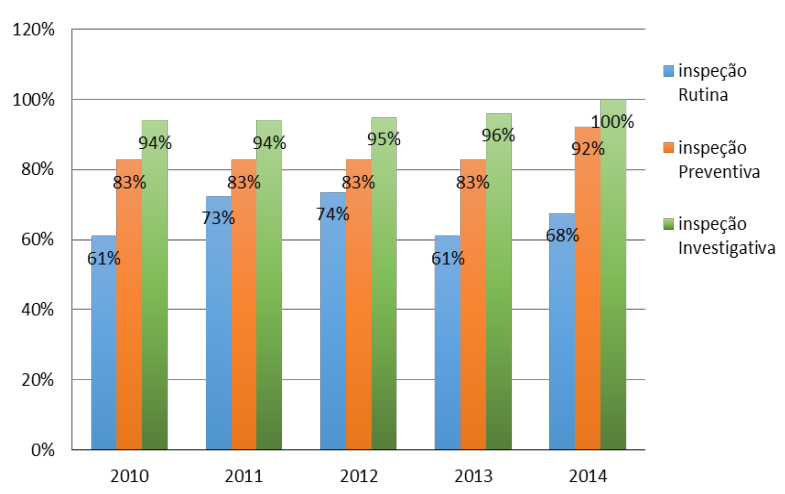

Gambar 1.2 Grafik Kinerja Pengawas Sekolah Dengan Tiga Program Utama

Sumber: Resultado Avaliação do Serviços Inspeção Geral do ME - RDTL, 2014

Berdasarkan pada Gambar 1.2 ditujukkan grafik pengukuran kinerja pengawas sekolah, Kinerja pengawas sekolah diukur dengan hasil evaluasi dari ketiga program tersebut, dari hasil evaluasi ketiga program belum linier. Hal ini disebabkan 
masih banyak kompetensi pengawas sekolah minim dalam melakukan inspeksi, hal ini menjadi kendala bagi para pengawas sekolah dalam melakukan program inspeksi sebab kemampuan dan pengetahuan yang dimiliki untuk melakukan inspeksi investigasi dan inspeksi pencegahan terhadap guru, kepala sekolah, dan staf administrasi sekolah masih rendah. Kompetensi yang baik harus didukung oleh level pendidikan yang cukup, level pendidikan para pengawas sekolah yang tersebar di 65 kecamatan dalam 13 kabupaten memiliki level pendidikan yang berbeda. Banyak diantaranya yang berpendidikan rendah.

Kinerja adalah hasil kerja yang dicapai baik secara kuantitas maupun kualitas sesuai dengan tanggug jawabnya, tidak melanggar hukum dan sesuai moral etika. Kinerja karyawan (desempenho funcionalismo) dapat diketahui atau dinilai berdasarkan kemampuan teknis dalam bekerja, sehingga karyawan tersebut akan memiliki pengalaman dan pelatihan sebelum bekerja. Kinerja juga merupakan suatu hasil kerja yang dicapai seorang dalam melaksanakan tugas-tugas yang dibebankan kepadanya berdasarkan kecakapan, kesanggupan, pengalaman, dan waktu (Rivai, 2009:125).

Kompensasi merupakan balas jasa yang diberikan oleh organisasi kepada pegawainya yang dapat bersifat finansial maupun non finansial. Pada periode yang tetap sistem kompensasi yang baik akan mampu memberikan kepuasan bagi individu. Jadi kebijaksanaan kompensasi merupakan kebijaksanaan yang paling penting dan strategis karena hal ini langsung berhubungan dengan peningkatan semangat kerja, kinerja karyawan. Kompensasi akan menciptakan suatu motivasi yang luar biasa dalam diri pegawai Handoko (2003:58). Hal ini didukun oleh beberapa penelitian (Omotayo et al. 2014, Alamdar et. al. 2012, Saani 2013, Ngui Thomas et al. 2014) Membuktikan bahwa paket kompensasi dengan kinerja karyawan memiliki hubungan yang sangat erat dan kompensasi berpengaruh signifian terhadap kinerja. Namun paket kompensasi harus dirancang khusu agar menarik kepuasan karyawan.

Kompetensi adalah karakteristik dasar seseorang (individu) yang mempengaruhi cara berpikir dan bertindak, membuat generalisasi terhadap segala situasi yang dihadapi serta bertahan cukup lama dalam diri manusia (Ruky, 2006). Dan didukung oleh beberapa penelitian Safwan 2014), Messah 2011, Edi Suwardji et al. (2012), membuktikan bahwa kompetensi berpengaruh terhadap kinerja, namun harus didukun oleh motivasi dan disiplin yang baik. Hal ini ditegas Johnson Ssekakubo (2014) pentingnya kompetensi manajerial untuk meningkatkan kinerja, Hasil penelitian terdahulu menyatakan bahwa kompensasi dan kompetensi berpengaruh terhadap kinerja karyawan dan organisasi secara signifikan.

Berdasarkan kajian pemikiran yang telah diuraikan, maka kerangka konseptual penelitian hubungan antara variabel kompensasi (X1) dan variabel kompetensi (X2) terhadap variable kinerja (Y) dapat dilihat pada Gambar 1 dibawah ini.

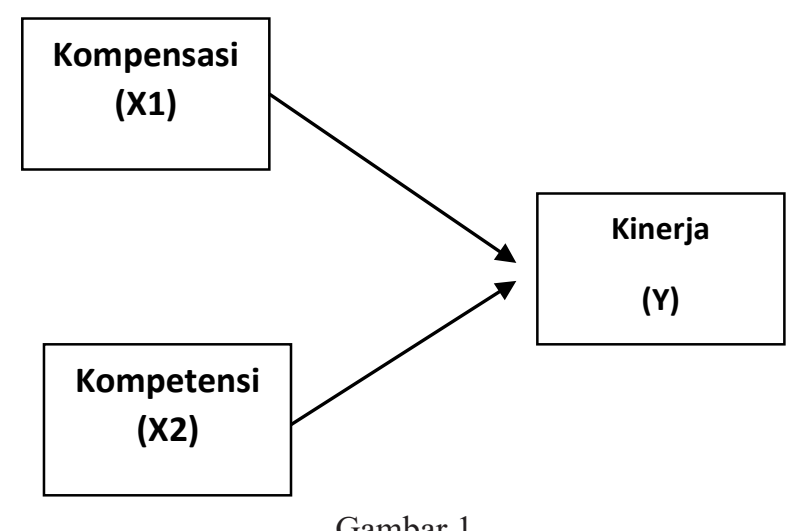

Konseptual Penelitian

\section{PENGARUH KOMPENSASI TERHADAP KINERJA}

Kompensasi memiliki hubungan yang sangat erat dengan kinerja, dengan kompensasi seorang tenaga kerja akan menjalankan pekerjaannya dengan lancar karena didukun dengan manjemen kompensasi yang memuaskan. Menurut Wibowo (2012), manajemen kompensasi sangat membantu organisasi untuk mencapai 
keberhasilan strategis dengan memastikan keadilan internal dan eksternal. Beberapa penelitian (Widyatmini; 2008, Suparwi; 2014, Susanta; 2013, Dhermawan; 2012, Wekesa; 2013, Odunlami; 2014), kompensasi memberikan konrtibusi terhadap kinerja, dengan managemen kompensasi yang baik maka pengaruh kompensasi sangat signifikan terhadap kinerja seorang karyawan.

Berdasarkan penjelasan teori penelitian terdahulu, maka dapat dirumuskan hipotesis sebagai berikut.

H1: Kompensasi berpengaruh positif dan signifikan terhadap kinerja

\section{PENGARUH KOMPETENSI TERHADAP KINERJA}

Kompetensi merupakan kemampuan seseorang dalam menyelesaikan suatu pekerjaan, kompetensi merupakan factor yang sangat mempengaharui kinerja karena dengan kompetensi yang bagus seseorang lebih berprestasi dalam menyeselesai pekerjaan sesuai dengan rencana dan hasil lebih memuaskan. Menurut McClelland dalam Robinson (2003) kompetensi berprestasi dibagi kedalam 3 komponen yakni kebutuhan berprestasi (achievment), kebutuhan afiliasi (affliation) dan kebutuhan akan kekuasaan (power) dapat digunakan untuk memotivasi seseorang untuk bekerja. Beberapa penelitian (Dhermawan; 2012, Keran; 2012, Emmyah; 2009, Fadli; 2011, Setiawati; 2009, Priasmara; 2013) membuktikan bahwa kompetensi sangat berpengaruh signifikan terhadap knerja, kompetensi juga signifikan terhadap kepuasan kerja pegawai dimana semakin baik kompetensi yang dimiliki oleh seorang pegawai, maka akan semakin baik pula kepuasan kerja yang dirasakan oleh pegawai tersebut. Kompetensi pegawai yang tinggi sangat diperlukan dalam suatu organisasi atau instansi agar tujuan organisasi atau instansi tersebut dapat tercapai.

Berdasarkan penjelasan teori dan penelitian terdahulu, maka dapat dirumuskan hipotesis sebagai berikut.

$\mathrm{H} 2$ : Kompetensi berpengaruh positif dan signifikan terhadap kinerja

\section{METODE PENELITIAN}

Penelitian dilakukan di Direção Inspeção Geral do Ministerio da Educação di Dili Timor-Leste. Penelitian ini mengambil judul pengaruh kompensasi dan kompetensi terhadap inerja pengawas. Populasi dalam penelitian ini adalah seluruh pengawas sekolah (inspector escolar) yang bekerja pada Direção Inspeção Geral do Ministerio da Educação di RDTL di Dili Timor-Leste, dengan jumlah pengawas sekolah (inspectors escolar) sebanyak 65 orang, sehingga seluruh pengawas sekolah (inspector escolar) diambil sebagai sampel (sampel jenuh atau sensus) sebagai responden. Data yang digunakan adalah data kuantitatif dan kualitatif, baik bersumber dari sumber primer mauun sumber sekunder.

Instrumen yang digunakan pada penelitian ini adalah kuesioner dalam bentuk pertanyaan tertutup yang sudah disediakan. Para responden tinggal memilih, dan menggunakan skala Likert mempunai gradasi (1 - 5 skala) dari sangat positif s/d sangat negatif, yang dapat berupa katakata. Data dikumpulkan dengan melakukan wawancara dan penyebaran kuesioner kepada para responden. Selanjutnya data yang telah terkumpul dianalisis dengan menggunakan analisis deskriftif dan analisis regresi linear berganda.

\section{HASIL DAN PEMBAHASAN KARAKTERISTIK RESPONDEN}

Karasteristik responden merupakan informasi yang digunakan dalam suatu populasi pada obyek penelitian yang dijelaskan berdasarkan alat uji statistik, selain itu karakteristik responden digunakan untuk memberi gambaran tentang jenis kelamin, umur, pendidikan, pangkat dan golongan serta masa kerja. Karakteristik responden disajikan pada Tabel 5.2 s/d Tabel 5.6.

Berdasarkan informasi yang disajian pada Tabel 5.2 dapat dijelaskan bahwa, responden berjenis kelamin laki-laki yaitu sebesar $88 \%$, sedangkan jenis kelamin wanita hanya 8 orang $12 \%$. Hal mengindikasikan bahwa tingginya peran kaum laki-laki sebagai 
Tabel 5.2

Karakteristik Responden Berdasarkan Jenis Kelamin

\begin{tabular}{|c|c|c|c|}
\hline \multicolumn{2}{|c|}{ Karakteristik } & $\begin{array}{l}\text { Jumlah } \\
\text { (Orang) }\end{array}$ & $\begin{array}{c}\text { Presentase } \\
(\%)\end{array}$ \\
\hline \multirow{3}{*}{ Jenis Kelamin } & Laki-laki & 57 & 88 \\
\hline & Perempuan & 8 & 12 \\
\hline & Jumlah & 65 & 100 \\
\hline \multirow{8}{*}{ Umur } & 26 - 30 tahun & 7 & 11 \\
\hline & $31-35$ tahun & 2 & 3 \\
\hline & 36 - 40 tahun & 5 & 8 \\
\hline & 41 - 45 tahun & 9 & 14 \\
\hline & 46 - 50 tahun & 20 & 31 \\
\hline & $>51$ tahun & 22 & 34 \\
\hline & Jumlah & 65 & 100 \\
\hline & SMA/Sederajat & 29 & 45 \\
\hline \multirow{4}{*}{ Pendidikan } & Diploma II & 4 & 6 \\
\hline & Diploma III & 25 & 38 \\
\hline & $\mathrm{S} 1$ & 6 & 9 \\
\hline & $\mathrm{S} 2$ & 1 & 2 \\
\hline \multirow{4}{*}{$\begin{array}{c}\text { Pangkat } \\
\text { dan Golongan }\end{array}$} & Jumlah & 65 & 100 \\
\hline & Golongan & Jumlah & $\%$ \\
\hline & $\begin{array}{c}\text { Teknik } \\
\text { Supervisi }\end{array}$ & 65 & 100 \\
\hline & Jumlah & 65 & 100 \\
\hline \multirow{4}{*}{ Masa kerja } & $3-5$ tahun & 9 & 13,84 \\
\hline & $6-8$ tahun & 14 & 21,53 \\
\hline & $9-11$ tahun & 42 & 64,61 \\
\hline & Jumlah & 65 & 100 \\
\hline
\end{tabular}

Sumber: Data primer diolah, 2015

pengawas sekolah pada Direção Inspeção Geral do Miniterio da Educação de Timor Leste. Pada karakteristik responden dari segi umur, pegawai memililki umur 51 tahun keatas (34 persen). Hal ini mengindikasikan bahwa para pengawas sekolah dipandang mampu melakukan tugas inspeksi terhadap guru-guru, kepala sekolah, maupun staf sekolah.

Pada karakteristik responden berdasarkan tingkat pendidikan menunjukkan bahwa pegawai yang bekerja pada Direção Inspeção Geral do Ministerio da Educação de Timor Leste sebagai pengawas sekolah kebanyakan telah mengegam pendidikan SMA/sederajat, yaitu sebesar 45 persen. Informasi ini menunjukkan pengetahuan dan wawasan para pengawas masih rendah dalam melakukan inspeksi terhadap guru maunpun staf administrasi sekolah. Berdasarkan pangkat dan golongan dapat dijelaskan bahwa, semua responden berada pada pangkat dan golongan A (teknik supervise). Ditinjau dari masa kerja Tabel 5.6, seluruh pegawas Sekolah dianggap telah berpengalaman dalam melakukan inspeksi pada guru dan staf tata usaha sekolah sebab para pengawas sekolah rata-rata sudah bekerja diatas 9 tahun $(64,61$ persen). Terkait dengan masa kerja, golongan para pegawas sekolah yang bekerja pada Direção Inspeção Geral do Ministerio da Educação de Timor Leste sebagian besar pada tingkat golongan A (Teknik Supervisi) yang ditunjukkan dalam 
Tabel 5.5 dengan distribusi sebesar 100\% persen.

\section{DESKRIPSI VARIABEL PENELITIAN}

Analisis deskriptif dilakukan untuk mendapatkan persepsi responden terhadap pernyataan yang diberikan tentang variabel- variabel penelitian. Analisis deskriptif dihitung berdasarkan persentase jawaban responden terhadap pernyataan-pernyataan dalam kuesioner penelitian dengan menggunakan nilai rerata setiap indikator yang diajukan untuk menggambarkan persepsi seluruh responden.

Tabel 5.7

Deskripsi Variabel Kinerja Pengawas Sekolah (Y)

\begin{tabular}{|c|c|c|c|c|c|c|c|c|}
\hline \multirow[t]{2}{*}{ No. } & \multirow{2}{*}{ Indikator/Pernyataan } & \multicolumn{2}{|c|}{ Jumlah } & \multicolumn{3}{|c|}{ Responden } & \multirow[t]{2}{*}{$\begin{array}{l}\text { Rata } \\
\text { Rata }\end{array}$} & \multirow[t]{2}{*}{$\begin{array}{l}\text { Keteran- } \\
\text { gan }\end{array}$} \\
\hline & & STS & $\mathrm{TS}$ & $\mathrm{N}$ & $\mathrm{S}$ & SS & & \\
\hline Y1 & Kualitas Kerja & 1 & 2 & 3 & 4 & 5 & & \\
\hline 1. & $\begin{array}{l}\text { menyelesaikan pekerjaan sesuai } \\
\text { waktu yang sudah di tentukan }\end{array}$ & 0 & 3 & 14 & 35 & 13 & 3.68 & Baik \\
\hline 2. & $\begin{array}{l}\text { Saya menyelesaikan pekerjaan } \\
\text { dengan penuh ketelitian }\end{array}$ & 0 & 0 & 9 & 3 & 22 & 3.94 & Baik \\
\hline 3. & $\begin{array}{l}\text { Saya dapat menggunakan fasilitas } \\
\text { kantor secara efektif }\end{array}$ & 0 & 0 & 3 & 19 & 43 & 4.03 & Baik \\
\hline \multirow[t]{2}{*}{4.} & $\begin{array}{l}\text { berorientasi pada kualitas saat } \\
\text { menyelesaikan pekerjaan }\end{array}$ & 1 & 1 & 5 & 37 & 21 & 3.88 & Baik \\
\hline & Rata-rata & \multicolumn{2}{|l|}{ Y1 } & & & & 3.88 & Baik \\
\hline Y2 & Kuantitas Kerja & & & & & & & \\
\hline 1. & $\begin{array}{l}\text { Saya selalu bekerja sesuai dengan } \\
\text { target yang di harapkan }\end{array}$ & 1 & 4 & 7 & 37 & 16 & 3.80 & Baik \\
\hline 2. & $\begin{array}{l}\text { Saya selalu menyelesaikan } \\
\text { pekerjaan sesuai dengan jabatan }\end{array}$ & 1 & 5 & 5 & 30 & 24 & 3.82 & Baik \\
\hline 3. & $\begin{array}{l}\text { Saya memiliki kemauan untuk } \\
\text { melakukan beberapa pekerjaan }\end{array}$ & 1 & 9 & 12 & 23 & 20 & 3.58 & Baik \\
\hline \multirow[t]{2}{*}{4.} & $\begin{array}{l}\text { Saya memiliki rasa tanggung jawab } \\
\text { atas pekerjaan }\end{array}$ & 0 & 1 & 0 & 20 & 44 & 4.37 & Sangat baik \\
\hline & Rata-rata & $\mathrm{Y} 2$ & & & & & 3.89 & Baik \\
\hline Y3 & \multicolumn{8}{|l|}{ Ketepatan Waktu } \\
\hline 1. & $\begin{array}{l}\text { menyelesaikan pekerjaan tepat pada } \\
\text { waktu yang telah ditentukan }\end{array}$ & 0 & 10 & 14 & 23 & 18 & 3.98 & Baik \\
\hline 2. & $\begin{array}{l}\text { hadir di tempat tugas dalam keadaan } \\
\text { apapun sesuai dengan waktu yang } \\
\text { telah ditentukan }\end{array}$ & 0 & 5 & 7 & 37 & 16 & 3.86 & Baik \\
\hline 3. & $\begin{array}{l}\text { memberikan pelayanan masyarakat } \\
\text { sesuai dengan bidang tugas }\end{array}$ & 0 & 1 & 8 & 28 & 28 & 4.06 & Baik \\
\hline 4. & $\begin{array}{l}\text { memberikan laporan hasil kerja } \\
\text { sesuai waktu yang telah ditentukan }\end{array}$ & 0 & 2 & 7 & 40 & 16 & 3.89 & Baik \\
\hline & Rata-rata & Y3 & & & & & 3.95 & Baik \\
\hline & Total indeks rata-rata & & $(\mathrm{Y})$ & & & & 3.91 & Baik \\
\hline
\end{tabular}




\section{Deskripsi Kinerja Pengawas Sekolah}

Kinerja pengawas sekolah direfleksikan melalui tiga indikator, yakni: kualitas kerja (empat item), kuantitas kerja (empat item), dan ketepatan waktu (empat item).

Tanggapan responden sebagaimana pada Tabel 5.7 menunjukkan bahwa sebagian besar responden memberikan tanggapan terhadap indikator kualitas kerja memperoleh nilai rerata sebesar 3.88 (baik), diikuti kuantitas kerja 3.89 (baik) dan indikator indikator ketepatan waktu mendapat tanggapan

Tabel 5.8

Deskripsi Variabel Kompensasi (X1)

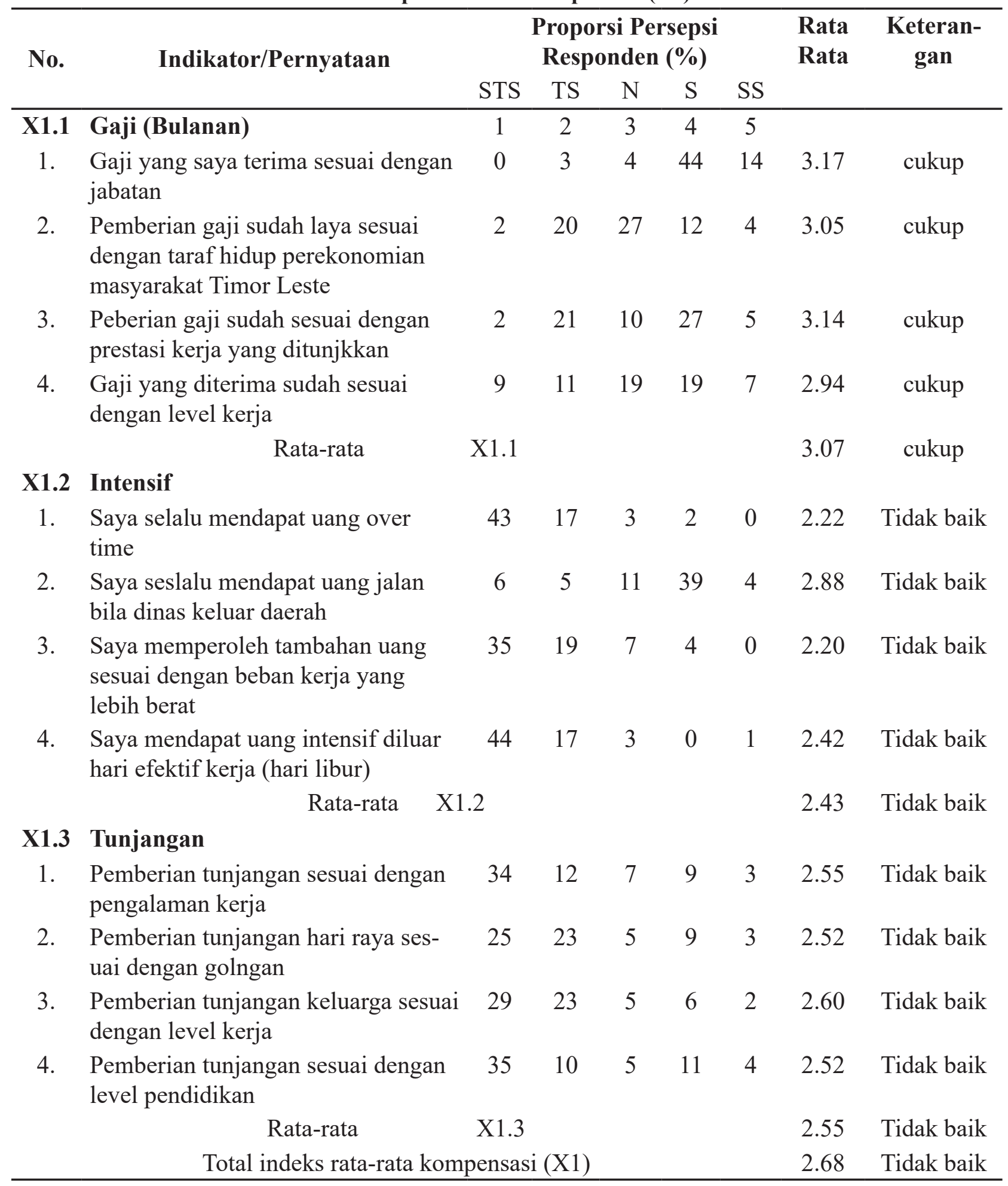


Tabel 5.9

Deskripsi Variabel Kompetensi (X2)

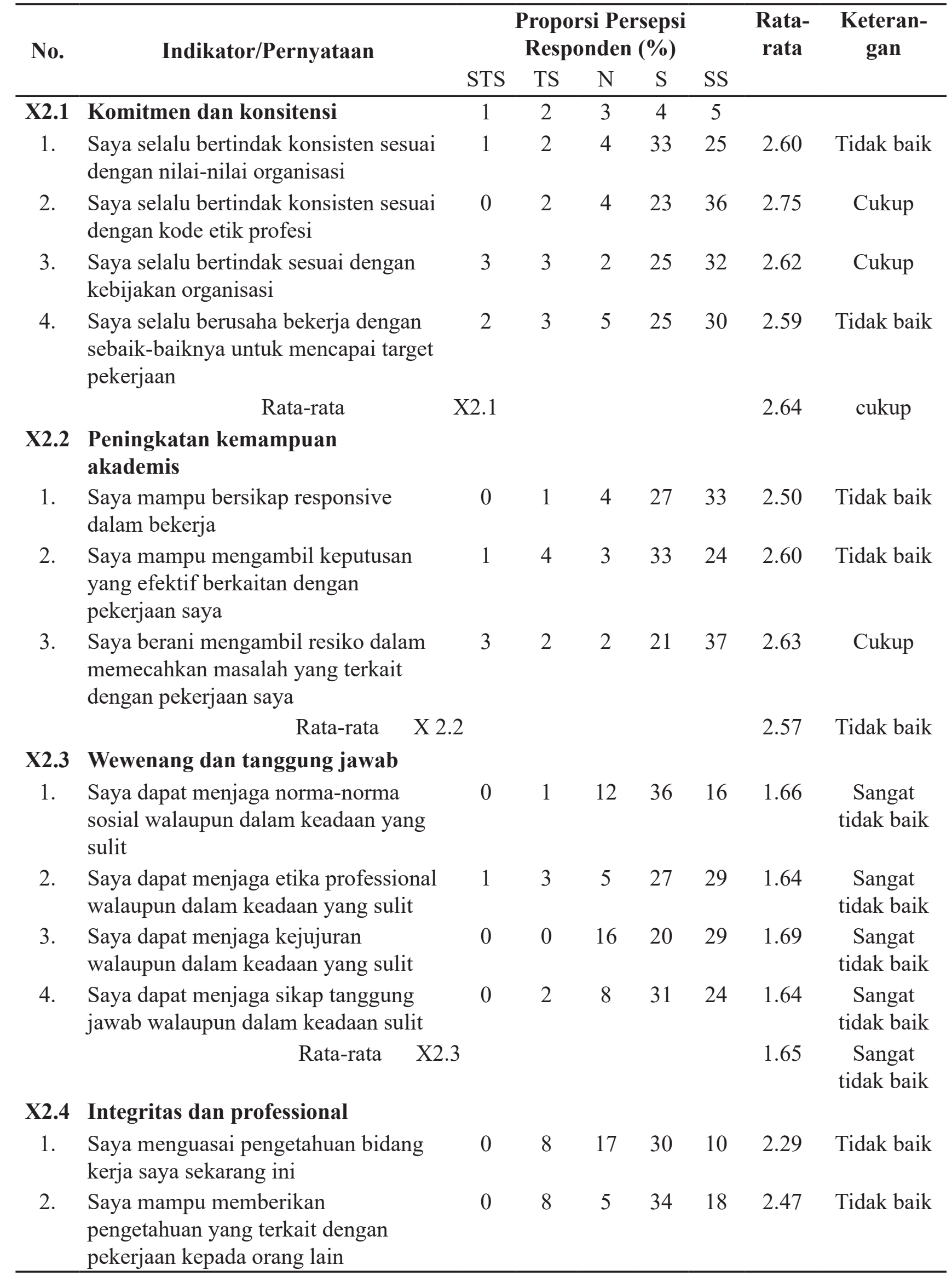


3. Pengetahuan yang saya miliki sangat $\quad \begin{array}{llllllll}0 & 1 & 1 & 26 & 37 & 2.82 & \text { Cukup }\end{array}$ membantu menyelesaikan tugas-

tugas saya

4. Pengentahuan yang saya miliki dapat $\quad \begin{array}{lllllllll}0 & 2 & 7 & 35 & 21 & 2.61 & \text { Cukup }\end{array}$ mengobservasi hasil integritas dan profesional

$$
\text { Rata-rata } \quad \text { X2.4 }
$$

2.54 Tidak baik

\section{X2.5 Metode Kerja Supervisi}

$\begin{array}{llllllllll}\text { 1. Saya dapat melakukan kunjungan ke } & 0 & 1 & 1 & 8 & 55 & 2.98 & \text { Cukup }\end{array}$ sekolah

2. Saya dapat melakukan kunjungan dikelas

3. Saya dapat melakukan pembicaraan $\quad \begin{array}{llllllll}0 & 0 & 7 & 11 & 47 & 2.85 & \text { Cukup }\end{array}$ individual dengan guru

4. Saya dapat rapat supervisi untuk $\quad \begin{array}{llllllllll}0 & 2 & 2 & 24 & 37 & 2.81 & \text { Cukup }\end{array}$ memperbaiki mutu pendidikan dan pengajaran

$$
\begin{array}{llll}
\text { Rata-rata } \quad \mathrm{X} 2.5 & 2.84 \quad \text { Cukup }
\end{array}
$$

\section{X2.6 Kedisiplinan dalam pengawasan}

1. Dapat melakukan pengawasan internal dan eksternal

2. Dapat melakukan pengawasan langsung dan tak langsung

3. Dapat melakukan pengawasan forma dan informal

4. Dapat melakukan pengawasan manajerial dan staf

$$
\text { Rata-rata }
$$

$\begin{array}{lllllll}0 & 7 & 4 & 22 & 32 & 2.71 & \text { Cukup } \\ 0 & 6 & 4 & 32 & 23 & 2.64 & \text { Cukup }\end{array}$

al

7

6

$\begin{array}{lll}12 & 23 & 17\end{array}$

2.60

Tidak baik

$\begin{array}{lllllll}0 & 2 & 8 & 21 & 34 & 2.23 & \text { Tidk baik }\end{array}$

2.54 Tidak baik

\section{X2.7 Keberanian pengambilan} keputusan

1. Keberanian dalam pengambilan keputusan untuk memperoleh keutungan maksimum

2. Keberanian dalam pengambilan keputusan untuk memaksimalkan keuntungan yang dapat memuaskan

3. Keberanian dalam pengambilan keputusan untuk bergerak bebas

4. Keberanian dalam pengambilan keputusan untuk kerja sama dalam pengambilan keputusan

$$
\text { Rata-rata }
$$


Table 5.10

Analisis Regresi Berganda

\begin{tabular}{|c|c|c|c|c|c|c|c|c|}
\hline \multicolumn{9}{|c|}{ Coefficients $^{\mathrm{a}}$} \\
\hline & \multirow[t]{2}{*}{ Model } & \multicolumn{2}{|c|}{$\begin{array}{c}\text { Unstandardized } \\
\text { Coefficients }\end{array}$} & \multirow{2}{*}{$\begin{array}{c}\text { Standardized } \\
\text { Coefficients } \\
\text { Beta }\end{array}$} & \multirow[t]{2}{*}{$\mathrm{t}$} & \multirow[t]{2}{*}{ Sig. } & \multicolumn{2}{|c|}{$\begin{array}{l}\text { Collinearity } \\
\text { Statistics }\end{array}$} \\
\hline & & B & Std. Error & & & & Tolerance & VIF \\
\hline \multirow[t]{3}{*}{1} & (Constant) & .075 & .873 & & .086 & .932 & & \\
\hline & $\mathrm{X} 1$ & 1.628 & .035 & .969 & 46.188 & .000 & .246 & 4.071 \\
\hline & $\mathrm{X} 2$ & .020 & .013 & .032 & 1.519 & .134 & .246 & 4.071 \\
\hline a. & ependent V & ble: Y & & & & & & \\
\hline
\end{tabular}

Sumber: Hasil Analisis

dengan nilai rerata sebesar 3.95 (baik). Hasil ini menunjukkan bahwa kinerja pengawas sekolah yang dicapai pada Direção Inspeção Geral do Miniterio Educação de Timor Leste dengan nilai indeks rata-rata baik.

\section{Deskripsi Variabel Kompensasi}

Variabel kompensasi diukur melalui tiga indkator, yaitu: gaji bulanan (empat item), intensif (empat item), dan tunjangan (empat item), deskripsi responden mengenai kompensasi pengawas sekolah disajikan pada tabel 5.4 .

Informasi pada Tabel 5.8, tanggapan para responden menunjukan indikator Gaji bulan dengan nilai indeks rerata 3.07 (cukup) hal ini mengindikasikan bahwa gaji bulanan yang diterima sudah sesuai dengan level kerja, sedangkan indikator intensif dan tunjangan tidak baik, dan total indeks ratarata variabel kompensasi 2.68 (tidak baik). Hal ini mengindikasikan bahwa selama ini para pengawas sekolah (inspector) tidak mendapatkan kompensasi berupa tunjangan atau intensif dari kementerian pendidikan Timor Leste. Oleh sebab itu sistem kompensasi harus dirancang dengan baik agar memberikan semangat kerja bagi para pengawas sekoah untuk menghasilkan kualitas kerja yang lebih baik.

\section{Deskripsi Variabel Kompetensi}

Kompetensi dalam penelitian ini golongkan melalui tiga indikator, yaitu: komitmen dan konsistensi (empat item), peningkatan kemampuan akademis (tiga item), wewenang dan tanggung jawab (empat item), integritas dan professional (empat item), metode kerja supervise (empat item), kedisiplinan dalam pengawasan (empat item), dan keberanian pengambilan keputusan (empat item). Deskripsi responden terhadap variabel kompetensi disajikan dalam Tabel 5.9 .

Informasi dalam Tabel 5.9 di atas menunjukkan bahwa para pengawas sekolah memiliki kompetensi relative cukup baik, didasarkan pada nilai persepsi rerata yang diperoleh dari tujuh indicator dengan nilai rerata sebesar 2.42 (Tidak Baik). Hal ini menunjukkan bahwa kemampuan akademis perlu ditingkatkan lagi untuk mendapatkan pengetahuan yang lebih luas agar mendorong keberanian para pengawas sekolah dalam pengambilan keputusan serta metode kerja supervise akan lebih bagus lagi.

\section{ANALISIS REGRESI BERGANDA}

Hasil pengolahan analisis regresi berganda dengan menggunakan software SPSS 17.0 adalah sebagai berikut.

Berdasarkan perhitungan spss tersebut diperoleh persamaan regresi linier berganda sebagi berikut:

Kinerja $(Y)=0.075+1.628\left(\mathrm{X}_{1}\right)+0.020\left(\mathrm{X}_{2}\right)$

Dari persamaan regresi linier berganda diatas diperoleh nilai konstanta sebesar 0.075. Artinya,jikavariabelKinerjapengawas sekolah (Y) tidak dipengaruhi oleh kedua variabel bebas kompensasi $\left(\mathrm{X}_{1}\right)$ dan kompetensi $\left(\mathrm{X}_{2}\right)$ bernilai nol, maka besarnya rata-rata kinerja pengawas sekolah akan bernilai 0.075 . Nilai 
Tabel.

Uji Multikolinieritas

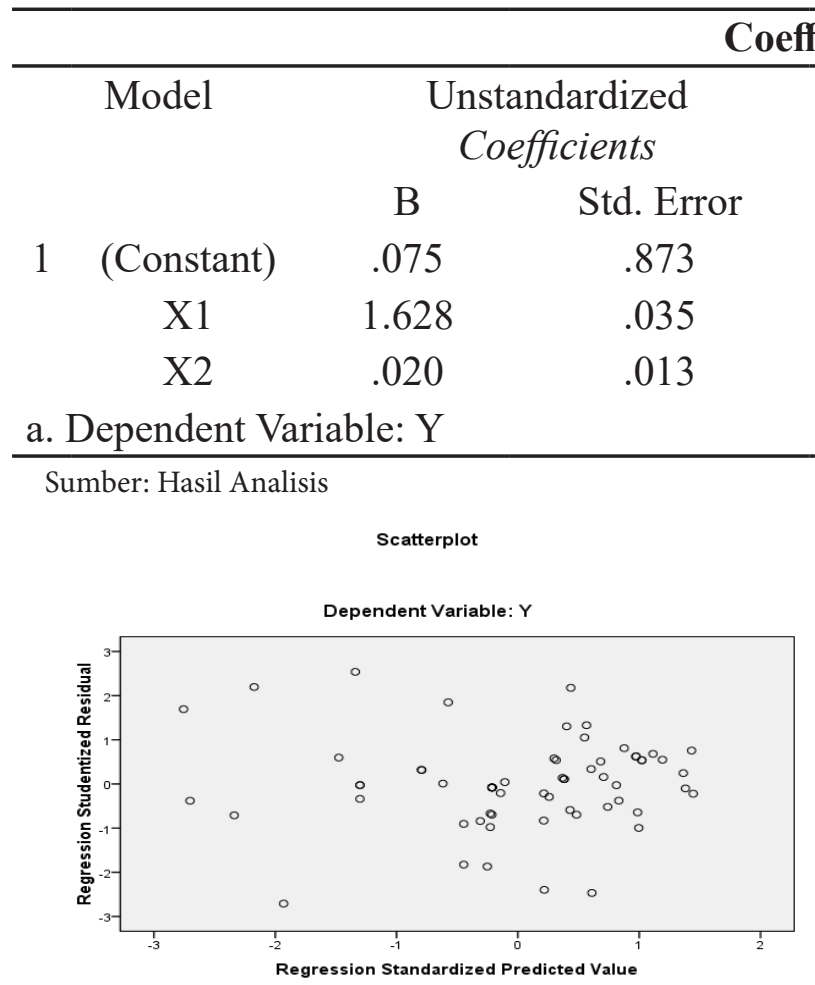

Gambar. Hasil Uji heteroskedastisitas

Sumber : Hasil analisis

koefisien regresi pada variabel-variabel bebas menggambarkan apabila diperkirakan variabel bebas naik sebesar satu unit dan nilai variabel bebas lainnya diperkirakan konstan atau sama dengan nol, maka nilai variabel terikat diperkirakan bisa naik atau bisa turun sesuai dengan tanda koefisien regresi variabel bebas.

Koefisien regresi untuk variabel bebas $\mathrm{X}_{1}$ (kompensasi) bernilai positif, menunjukkan adanya hubungan yang searah antara kompensasi $\left(\mathrm{X}_{1}\right)$ dengan kinerja pengawas sekolah (Y). Koefisien regresi variabel $\mathrm{X}_{1}$ sebesar 1.628 mengandung arti untuk setiap pertambahan kompensasi $\left(\mathrm{X}_{1}\right)$ sebesar satu satuan akan menyebabkan meningkatnya kineja pengawas sekolah (Y) sebesar 1.628. Koefisien regresi untuk variabel bebas $\mathrm{X}_{2}$ (kompetensi) bernilai positif, menunjukkan adanya hubungan yang searah antara komptensi $\left(\mathrm{X}_{2}\right)$ dengan kinerja pengawas sekolah (Y). Koefisien regresi variabel $\mathrm{X}_{2}$ sebesar 0.020 mengandung arti untuk setiap pertambahan kompetensi $\left(\mathrm{X}_{2}\right)$ sebesar satu satuan akan menyebabkan meningkatnya

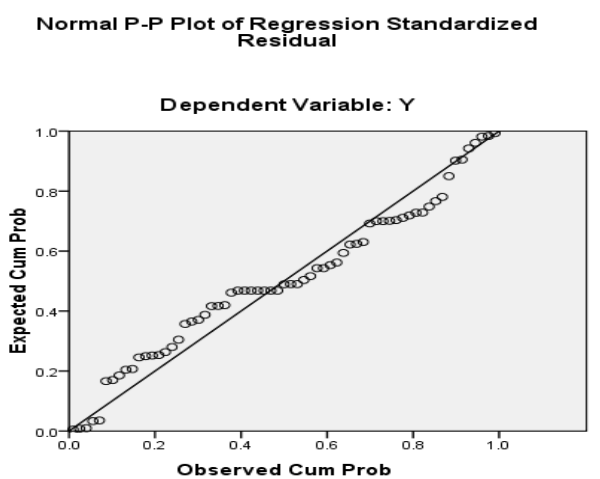

Gambar. Hasil Uji heteroskedastisitas

Sumber : Hasil analisis

kinerja pengawas sekolah (Y) sebesar 0.020.

\section{UJI ASUMSI KLASIK}

Untuk melakukan uji terhadap model regresi dilakukan uji asumsi klasik. Hasil pengujian asumsi klasik dengan menggunakan Program SPSS ditunjukkan pada table berikut.

Syarat uji normalitas dengan normal probability plot yaitu penyebaran data harus berada disekitar wilayah garis diagonal dan mengikuti arah garis diagonal. Berdasarkan gambar di atas dapat disimpulkan bahwa data dalam penelitian ini memenuhi syarat normal probability plot sehingga model regresi dalam penelitian memenuhi asumsi normalitas (berdistribusi normal). Sesuai dengan ketentuan uji multikolinieritas, jika nilai VIF kurang dari 10 maka tidak terdapat korelasi. Berdasarkan tabel di atas dapat dilihat bahwa nilai VIF yaitu 4,071 kurang dari 10. Sehingga dalam penelitian ini tidak terdapat multikolinieritas dalam data. Artinya antara variabel bebas (kompensasi $\left(\mathrm{X}_{1}\right)$ dan kompetensi $\left(\mathrm{X}_{2}\right)$ tidak saling mengganggu 
Tabel.

Uji Multikolinieritas

\begin{tabular}{|c|c|c|c|c|c|c|c|c|c|c|}
\hline \multicolumn{11}{|c|}{ Model Summary ${ }^{b}$} \\
\hline Model & $\mathrm{R}$ & R Square & Adjusted & Std. Error of & & Change S & tatist & & & Durbin- \\
\hline & & & & & $\begin{array}{l}\text { R Square } \\
\text { Change }\end{array}$ & $\begin{array}{c}\text { F } \\
\text { Change }\end{array}$ & df1 & $\mathrm{df} 2$ & $\begin{array}{c}\text { Sig. F } \\
\text { Change }\end{array}$ & \\
\hline 1 & $.997 \mathrm{a}$ & .993 & .993 & .91344 & .993 & 4595.084 & 2 & 62 & .000 & 1.625 \\
\hline \multicolumn{11}{|c|}{ a. Predictors: (Constant), X2, X1 } \\
\hline
\end{tabular}

Sumber: Hasil Analisis

atau mempengaruhi. Selanjutnya, Dari gambar diatas dapat diketahui bahwa tidak terjadi heteroskedastisitas sebab tidak ada pola yang jelas serta titik-titik menyebar di atas dan di bawah angka 0 pada sumbu Y. sehingga dapat dikatakan uji heteroskedastisitas terpenuhi. Artinya dalam fungsi regresi di penelitian ini tidak muncul gangguan karena varian yang tidak sama.

\section{KOEFISIEN DETERMINASI}

Koefisien determinasi pada intinya mengukur seberapa jauh kemampuan model dalam menerangkan variasi variabel. Koefisien determinasi ini digunkan karena dapat menjelaskan kebaikan dari model regresi dalam variabel dependen. Semakin tinggi nilai koefisien determinasi maka akan semakin baik pula kemampuan variabel independen dalam menjelaskan variabel dependen. Nilai koefisien determinasi adalah antara nol dan satu. Nilai $\mathrm{R}^{2}$ yang kecil berarti kempuan variabel-variabel indepnden dalam menjelaskan variasi variabel dependen amat terbatas. Nilai yang mendekati satu berarti variabel-variabel independen memberikan hampir semua informasi yang dibutuhkan untuk memprediksikan variasi variabel dependen. Dengan menggunakan SPSS 17.0 diperoleh koefisien determinasi sebagai berikut:

Berdasarkan hasil output SPSS tersebut dapat dilihat bahwa nilai koefisien determinasi atau R Square sebesar 0,933 atau 93,3\%. Hal ini menunjukan bahwa variabel yang diteliti (kompensasi dan kompetensi) memberikan pengaruh terhadap kinerja pengawas sekolah sebesar 93,3 sedangkan sisanya $6,7 \%$ dipengaruhi variabel yang tidak diteliti (variabel pengganggu).

\section{PEMBAHASAN \\ Pengaruh Kompensasi terhadap Kinerja Pengawas Sekolah}

Kompensasi kebijaksanaan yang paling penting dan strategis karena hal ini langsung berhubungan dengan peningkatan semangat kerja dan kinerja. Kompensasi bagi organisasi atau perusahaan berarti penghargaan atau ganjaran pada para pekerja yang telah memberikan kontribusi dalam mewujudkan tujuannya, melalui kegiatan yang disebut kerja (Nawawi, 2009:315).

Kompensasi dapat digunakan untuk membandingkan kesejahteraan atau standar hidup seseorang yang bekerja dalam organisasi. Dengan merancang sistem kompensasi yang bagus bagi pengawas sekolah, maka seorang pengawas sekolah akan merasa hidupnya lebih sejahtera, jika seorang pengawas sekolah yang telah merasakan hidupnya sejahtera akan termotivasi dalam menjalankan tugasnya lebih baik. Berdasarkan analisis yang dilakukan kompensasi merupakan salah satu faktor yang mempengaruhi kinerja pengawas sekolah. Peningkatan pemberian kompensasi akan diikuti dengan peningkatan kinerja pengawas sekolah. Bahkan berdasarkan analisis tersebut kompensasi mempengaruhi kinerja pengawas sekolah secara signifikan.

Hal ini sejalan dengan penelitian (Widyatmini \& Hakim, 2008) kompensasi 
sangat signifikan mempengaruhi kinerja pegawai. Beberapa penelitian lain seperti: (Widyatmini; 2008, Suparwi; 2014, Susanta; 2013, Dhermawan; 2012, Wekesa; 2013, Odunlami; 2014), menyatakan bahwa kompensasi memberikan konrtibusi terhadap kinerja, dengan managemen kompensasi yang baik maka pengaruh kompensasi sangat signifikan terhadap kinerja seorang karyawan.

\section{Pengaruh Kompetensi Terhadap Kinerja Pengawas Sekolah}

Kompetensi adalah karakteristik dasar seseorang (individu) yang mempengaruhi cara berpikir dan bertindak, membuat generalisasi terhadap segala situasi yang dihadapi serta bertahan cukup lama dalam diri manusia (Ruky, 2006). Kompetensi merupakan salah satu indikator keberhasilan untuk menigkatkan kinerja pengawas sekolah. Dengan demikian makin tingginya kompetensi biasanya makin tinggi pula kinerja, sedangkan apabila kompetensi seseorang rendah maka itu menggambarkan pekerjaan dihasilkan kurang bagus.

Berdasarkan hasil analisis yang telah dilakukan menunjukan bahwa kompetensi tidak mempengaruhi kinerja pengawas sekolah secara seignifikan. Berdasarkan data yang dijadikan dasar penelitian ini dapat dilihat bahwa hubungan antara kompetensi dengan kinerja pengawas sekolah bersifat fluktuatif. Artinya ada saat dimana para pengawas sekolah berkompetensi bagus namun kinerja pengawas sekolah bisa menurun. Sehingga dapat disimpulkan bahwa kompetensi tidak berpengaruh secara segnifikan terhadap kinerja pengawas sekolah. Hal ini tidak sejalan dengan penelitian (Setiawati, 2009) Kompetensi berpengaruh signifikan terhadap kinerja Dosen.

Hasil penelitian ini sejalan dengan hasil penelitian . Beberapa penelitian (Dhermawan; 2012, Keran; 2012, Emmyah; 2009, Fadli; 2011, Setiawati; 2009, Priasmara; 2013) membuktikan bahwa kompetensi sangat berpengaruh signifikan terhadap knerja, kompetensi juga signifikan terhadap kepuasan kerja pegawai dimana semakin baik kompetensi yang dimiliki oleh seorang pegawai, maka akan semakin baik pula kepuasan kerja yang dirasakan oleh pegawai tersebut.

\section{SIMPULAN DAN SARAN}

Berdasarkan hasil analisis tentang pengaruh Kompensasi Dan Kompetensi Terhadap Kinerja Pengawas Sekolah pada Direção Inspeção Geral di Kementrian Pendidikan Timor Leste, maka diperoleh kesimpulan sebagai berikut. Kompensasi berpengaruh positip signifikan terhadap kinerja pengawas. Artinya bahwa semakin baik tingkat kompensasi maka kinerja pengawas pada Sekolah pada Direção Inspeção Geral di Kementrian Pendidikan Timor Leste akan semakin meningkat. Kompetensi berpengaruh positip tidak signifikan terhadap kinerja pengawas Direção Inspeção Geral di Kementrian Pendidikan Timor Leste. Hasil penelitian menjelaskan bahwa kompetensi yang dimiliki para pengawas belum mampu meningkatkan kinerja pengawas secara nyata.

Berdasarkan kesimpulan yang diperoleh dan telah diuraikan diatas, maka dapat diajukan saran-saran sebagai pelengkap terhadap hasil penelitian sebagai berikut. Meningkatkan kompetensi para pengawas meliputi peningkatan kemampuan akademis, wewenang dan tanggung jawab, integritas dan professional, memberikan pelatihan supervise, kedisiplinan, dan memberikan pembelajaran terkait dengan keberanian dalam mengambil resiko. Meningkatkan pemberian kompensasi yang masih dianggap tidak memadai (cukup). Bahkan sebagian para pengawas mempersepsikan bahwa insentif dan tunjangan yang selama ini diberikan kepada mereka dinilai tidak memadai dan kurang mendapat perhatian.

\section{IMPLIKASI PENELITIAN}

Hasil penelitian menunjukkan bahwa hasil penelitian ini sesuai dengan beberapa hasil penelitian terdahulu. Dengan demikian secara teoritis penelitian ini mampu menambah dan memperkaya referensi penelitian pada bidang manajemen sumber daya manusia yang 
terkait dengan pengaruh antara kompetensi dan kompentensi terhadap kinerja pengawas.

Berdasarkan hasil analisis yang telah dilakukan, secara praktis penelitian ini memberikan kontribusi penting bahwa kompensasi yang dipersepsikan tidak baik menghasilkan kinerja yang baik. Terlihat bahwa unsur - unsur kompensasi yang dipersepsikan tidak baik adalah adanya insentif dan tunjangan yang dirasakan belum memadai oleh sebagian besar para pengawas. Namun demikian, bila memp[erhatikan jumlah gaji yang diberikan mereka merasakan cukup yang artinya bahwa gaji yang diterima selama ini oleh para pengawas dinilai sudah mencukupi.

Berdasarkan hasil analisis juga dapat diberikan gambaran bahwa kompetensi bukanlah menjadi penentu utama dalam melakukan pekerjaan sebagai pengawas sekolah. Hal ini dibuktikan dengan persepsi para pengawas yang masih menyatakan bahwa kompetensi mereka rata - rata tidak baik. Namun kedepan diharapkan ada kebijakan dari pemerintah untuk selalu melakukan usahausaha peningkatan kompetensi para pengawae supaya mereka dapat bekerja lebih optimal.

\section{REFERENSI}

Ashari, Purbayu Budi Santoso. 2005. Analisis statistic dengan Microsoft exel dan SPSS. Yogyakarta. : Andi Offset

Bernadin, J. (2003). Human Resource Management, An Experiential Approach, Third Edition. Boston: Mc. Graw-Hill.

\section{(2006). Human Resource} Management, An Experiental Approach. Fourth Edition, Florida: Mc. Graw-Hill.

Dhermawan, Anak Agung Ngurah Bagus (2012). Pengaruh Motivasi, Lingkungan Kerja, Kompetensi, Dan Kompensasi Terhadap Kepuasan Kerja Dan Kinerja Pegawai Di Lingkungan Kantor Dinas Pekerjaan Umum Provinsi Bali. Jurnal
Manajemen, Strategi Bisnis, dan Kewirausahaan Vol. 6, No. 2

Edi Suswardji, R. H. (2012). Hubungan Kompetensi Dan Disiplin Kerja Terhadap Kinerja Tenaga Kependidikan Universitas Singaperbangsa Karawang. Jurnal Manajemen Vol.10 No.1.

Gaol, C. J. (2014). A to Z Human Capital Manajemen Sumber Daya Manusia. Jakarta: PT. Grasindo.

Gomez, M. R. (2001). Managing Human Resource. New Jersey: Prentice Hall.

Gorda, I Gusti Ngurah, (2006), Manajemen Sumber Daya Manusia, Edisi Revisi, Penerbit Astabrata Bali

Ghozali, I. (2001). Analisis Multivanate dengan program SPSS. Edisi ke 2. Universitas Diponegoro

Ghozali, H. Imam (2007). Manajemen Risiko Perbankan. Semarang : BPUNDIP

Handoko, T. Hani. 2003. Manajemen. Cetakan Kedelapanbelas. Yogyakarta: BPFE.

Hasibuan, Malayu S. P. 2008. Manajemen Sumber Daya Manusia. Jakarta: PT. Bumi Aksara

Ellis, Idemobi O. C. (2011). Compensation Management As Tool For Improving Organizational Performance In The Public Sectors:. Sacha Journal of Policy and Strategic Studies Volume 1, 109-120.

Emmyah (2009). Pengaruh Kompetensi Terhadap Kinerja Pegawai Pada Pliteknik Negeri Ujung Padang. Sekolah Tinggi Ilmu Administrasi LembagaAdministrasi Negara Makssar

Fadli, Inneke Qamariah (2011). Pengaruh 
Perencanaan Dan Kompetensi Karyawan Terhadap Kinerja Karyawan Pada Pt. Indonesia Asahan Alumunium Kuala Tanjung. Jurnal Ekonom, Vol 14, No 2.

Kaushiki Tripathi, M. A. (2014). Competency Based Management In Organizational Context: A Literature Review. Global Journal of Finance and Management. ISSN 0975-6477 Volume 6 Number 4, 349-356.

Keran, Kristina Nugi (2012). Pengaruh Motivasi Kerja, Kompetensi, dan Kompensasi Terhadap Kinerja Karyawan Di Yayasan Bintang Timur Tangerang. Tesis Universitas Esa Unggul Jakarta

Mahmudi. (2005). Manajemen Kerja Sektor Publik. Akademik Manajemen Yogyakarta: Perusahaan YKPN.

Mangkunegara, P. A. (2006). Evaluasi Kinerja Sumber Daya Manusia Perusahaan. Bandung: PT. Refika Aditama.

(2007). Manajemen Sumber Daya Manusia Perusahaan. Bandung: PT. Remaja Rosdakarya.

Mathis, Roberth L. \& Jackson, John H. (2002). Manajemen Sumber Daya Manusia. Edisi Pertama Jakarta: Salembah Empat.

(2009). Human Resource Management. Jakarta: Salemba Empat.

Michael, Leibunon and Weintein, Harold P., 1993. Money is Everything, Annual Report HR.

Moeheriono. (2009). Pengukuran Kinerja Berbasis Kompetensi. Bogor: Penerbit Ghalia Indonesia.

Nawawi, Hadari. 2009. Manajemen Sumber
Daya Manusia. Jakarta: Gramedia Pustaka Utama.

Ngui Thomas, E. M. (2014). Effect Of Reward And Compensation Strategies On The Performance Of Commercial Banks In Kenya. International Journal of Education and Research ISSN: 2201-6333 Vol. 2 No. 1.

Odunlami, B. (2014). Compensation Management and Employees Performance in the Manufacturing Sector, A Case Study of a Reputable Organization in the Food and Beverage Industry. International Journal of Managerial Studies and Research (IJMSR) ISSN 2349-0330, Volume 2, PP 108-117

Omotayo Adewale Osibanjo, A. A. (2014). Compensation packages: a strategic tool for employees' Performance and retention. Leonardo Journal of Sciences, ISSN 1583-0233, 65-84.

Priasmara, Bambang (2013). Hubungan Antara Kompetensi Pegawai Dengan Kinerja Pegawai Di Kantor Badan Kepegawaian Daerah Kabupaten Tana Tidung. Ejournal Pemerintahan Integratif, ISSN 2337-8670, Ejournal.Pin.Or.Id

Rivai, H. Veithzal. (2005). Manajemen Sumber Daya Manusia Untuk Perusahaan dari Teori ke Praktek. Cetakan Pertama. Jakarta: PT. RajaGrafindo Persada.

(2008). MSDM untuk Perusahaan (Dari Teori ke Praktik). Edisi satu. Jakarta: PT Raja Grafindo Persada (2009). Manajemen Sumber Daya Manusia untuk Perusahaan Dari Teori ke Praktek, Edisi Kedua. Jakarta: PT. RajaGrafindo Persada. 
Robbins, S. P. (2001). Essentials of Organization Behaviour (7th ed). US: Prentice Hall.

Robinson, S. (2003). Organizational Behavior, Tenht Edition. Benjamin Molan (Penerjemah) Perilaku Organisasi. Jakarta: PT. Indeks Kelompok Gramedia.

Ruky, A. S. (2006). Sumber Daya Manusia Berkualitas, Mengubah Visi Misi Menjadi Realitas, Cetakan Kedua. Jakarta: PT Gramedia Pustaka Utama.

Saani, A.-J. (2013). Influence of Compensation and Supervision on Private Basic School Teachers Work Performance in Ashaiman Municipality. International Journal of Business and Social Science Vol. 4 No. 17 Special Issue.

Safwan. (2014). Pengaruh Kompetensi Dan Motivasi Terhadap Kinerja Pengelolaan Keuangan Daerah. Jurnal Akuntansi ISSN 2302-0164 Volume 3, No. 1, pp. 133- 139.

Sedarmayanti. (2007). Manajemen Sumber Daya Manusia. Bandung: PT. Refika Aditama.

- (2009). Sumber Daya Manusia dan Produktivitas Kerja. Bandung: Ilham Jaya.

Setiawati, Tati (2009). Pengaruh Kompetensi Kerja Terhadap Kinerja Dosen. Media Pendidikan Gizi Dan Kuliner Vol.1, No.1

Simamora, H. (2004). Manajemen Sumber Daya Manusia, Edisi Ketiga, Cetakan Pertama. Yogyakarta: STIE-YKPN.

Simanjuntak, P. J. (2005). Pengantar Ekonomi Sumber Daya Manusia. Edisi Ketiga jakarta: STIE-YKPN.
Solimun. (2008). Pemodelan Persamaan Struktural Pendekatan PLS. Malang: Penerbit UB Fakultas Ekonomi.

Sudarmanto. (2009). Kinerja dan Pengembangan Kompetensi SDM. Yogyakarta: Pustaka Pelajar.

Sugiyono. (2003). Metode Penelitian bisnis. cetakan kelima. CV. Alfabeta. Jakarta.

--------- (2012). Metode Penelitian Kuantitatif \& Kualitatif dan R \& D. CV. Alfabeto. Bandung

Suparwi (2014). Pengaruh Kompetensi Dan Kompensasi Terhadap Kinerja Dengan Mediasi Kepuasan Kerja Pada Guru Madrasah Aliyah Swasta Di Kabupaten Pati. Tesis Fakultas Ekonomi Universitas Muria Kudus

Susanta, I Wayan Niko (2013). Pengaruh Kompensasi Dan Kepemimpinan Terhadap Kinerja Karyawan Pada Jasa Konstruksi Di Denpasar. Jurnal Ilmiah Elektronik Infrastruktur Teknik Sipil, Volume 2, No. 2

Wekesa, J. N. (2013). Effect of Compensation on Performance of Public Secondary School Teachers in Eldoret Municipality Kenya. International Journal of Scientific and Research Publications, ISSN 2250-3153, Vol 3.

Wibowo. (2008). Manajemen Kinerja. Jakarta: PT. RajaGrafindo Persada.

(2010). Manajemen Kinerja. Edisi Ketiga Jakarta: PT. Rajawali Pers.

(2012). Manajemen Kinerja. Jakarta: PT. RajaGrafindo Persada.

Widyatmini \& Luqman Hakim (2008). Hubungan Kepemimpinan, Kompensasi Dan Kompetensi Terhadap Kinerja Pegawai Dinas 
Kesehatan Kota Depok. Jurnal Ekonomi Bisnis No. 2 Vol. 13

Yunus, E. (2009). Pengaruh Kompetensi Sumber Daya Manusia Terhadap Kinerja Pegawai Kppbc Tipe Madya Pabean Tanjung Perak Surabaya. Jurnal Ekonomi dan Keuangan ISSN 1411-0393. 